\title{
Austeridade fiscal e seus efeitos no Complexo Econômico-Industrial da Saúde no contexto da pandemia da COVID-19
}

\author{
Fiscal austerity and its effects on the Brazilian \\ Health Economic-Industrial Complex in the \\ context of the COVID-19 pandemic
}

\author{
La austeridad fiscal y sus efectos sobre el \\ Complejo Económico-Industrial de la Salud \\ en Brasil en el contexto de la pandemia \\ de COVID-19
}

\author{
Erika Santos Aragão 1,2,3 \\ Francisco Rózsa Funcia 2,3
}

doi: 10.1590/0102-311X00100521

\section{Introdução}

A estruturação de um Complexo Econômico-Industrial da Saúde (CEIS) brasileiro robusto, capaz de reduzir a dependência tecnológica nesta área, requer articulação intersetorial com a presença de financiamento em diferentes esferas (desenvolvimento produtivo, saúde, educação, pesquisa e desenvolvimento etc.).

No país, o final da década de 1990 foi marco do início de uma série de políticas que buscaram a aproximação das relações entre política de saúde, política científica e tecnológica, e política de desenvolvimento produtivo, tendo o CEIS 1,2 passado a ser tratado como componente estrutural da política de saúde e a saúde como um segmento importante para o desenvolvimento econômico. No entanto o conjunto de esforços não se traduziu efetivamente em redução da nossa dependência externa de produtos para a saúde. Este quadro se agravou a partir de 2016, quando o país começou a adotar políticas de austeridade fiscal que tem promovido o desmonte do setor público no país.

O Sistema Único de Saúde (SUS), criado na Constituição Federal de 1988, componente central do CEIS, é vítima de subfinanciamento desde sua origem. Nasceu no contexto de redução do Estado nas economias centrais diante de recomendações nesta mesma direção para a América Latina, popularmente conhecidas como "Consenso de Washington", cuja máxima era a redução do papel do Estado e medidas amargas para sua concretização. Corte de gastos públicos para a redução da dívida pública e reforma fiscal focada na redução da tributação das empresas eram o cerne dessa proposta. Isso somado à ampliação do setor privado em todas as áreas mediante privatizações e abertura comercial e econômica, visando a redução do protecionismo para ampliar a abertura das economias para o investimento estrangeiro 3,4 .

O ambiente muito distinto de sistemas públicos universais criados em momentos de expansão econômica, ampla participação do Estado e disponibilidade de financiamento de longo prazo, como no Canadá, em 1947 5, e no Reino Unido (Serviço Nacional de Saúde - NHS, em inglês), em 19486. Financiamento público insuficiente para redução da dependência tecnológica também esteve presente nos segmentos produtivos, educação e ciência e tecnologia.

No contexto da pandemia da COVID-19, essa dependência tecnológica do Brasil se traduziu na escassez de respiradores, medicamentos necessários à intubação dos pacientes, vacinas, entre vários outros insumos necessários para o enfrentamento da pandemia.
1 Instituto de Saúde Coletiva, Universidade Federal da Bahia, Salvador, Brasil. 2 Universidade Municipal de São Caetano do Sul, São Caetano do Sul, Brasil. 3 Associação Brasileira de Economia da Saúde, Rio de Janeiro, Brasil.

Correspondência E. S. Aragão Instituto de Saúde Coletiva, Universidade Federal da Bahia.

Rua Basílio da Gama 316, Salvador, BA 40110-040, Brasil.

erikapecs@gmail.com 
A contradição entre o modelo redistributivo na Constituição Federal de 1988 e os baixos níveis de gastos públicos em saúde, inclusive relativos à produção de bens e insumos, se agravou a partir da Emenda Constitucional no 95/2016 7, que congelou os gastos públicos por 20 anos. Esta e outras medidas, como as reformas previdenciária e trabalhista, e mais recentemente a Emenda Constitucional no 109/2021 8, hegemônicas na agenda do atual governo, têm desidratado todo o sistema público.

Este texto traz breve reflexão sobre a relação entre as políticas de austeridade fiscal, seus efeitos nas ações e serviços de saúde, bem como no papel do SUS, previsto na Lei no 8.080/1990 9, na formulação de política de saúde destinada a promover, nos campos econômico e social, o acesso universal e igualitário em todos os níveis de assistência; e a formulação da política de medicamentos, equipamentos, imunobiológicos e outros insumos de interesse para a saúde e a participação na sua produção. Aponta, ainda, como esta opção política por uma política de austeridade focada na redução de gastos públicos pode comprometer o direito universal à saúde de forma equitativa.

\section{Dependência tecnológica e o acesso a produtos para a saúde}

A pandemia da COVID-19, a maior crise mundial desde a década de 1930, deixou claro que ter capacidade científica, tecnológica e industrial voltada às necessidades de saúde, bem como sistemas de saúde com infraestrutura e financiamento adequados são garantia de vida. Ao mesmo tempo, tornou mais evidente a necessidade de aumento dos gastos sociais, implementadas na maior parte dos países centrais e em alguns países da América Latina 10.

Com a disseminação do vírus em todo o mundo, as medidas não farmacológicas têm se mostrado fundamentais para o controle da pandemia. Uso de máscara, distanciamento social, cancelamento de eventos públicos, fechamento de escolas e empresas, entre outras medidas, têm sido desencorajadas pelo Governo Federal. Assim, o acesso a respiradores, medicamentos para intubação, oxigênio, insumos como máscaras cirúrgicas, luvas, testes para diagnóstico, entre outras tecnologias, como vacinas, tornam-se ainda mais importantes para a redução da morbimortalidade pela doença. Porém a escassez desses itens evidenciou como a dependência tecnológica externa do país na área de produtos para a saúde deixou sua população vulnerável 11 .

Num contexto de aprofundamento da internacionalização e concentração do capital, essa é uma trajetória preocupante. De acordo com o Índice de Inovação Global 12, dez países concentram 88\% das patentes na área de saúde (Estados Unidos, China, Japão, Coreia do Sul, Alemanha, Suíça, França, Reino Unido, Países Baixos e Israel). Isto impõe desafios ao Brasil para a articulação e o desenvolvimento da base produtiva e tecnológica da saúde, especialmente de capital nacional, particularmente no contexto de redução dos investimentos públicos nestes campos, com desmonte de políticas intersetoriais importantes no âmbito do Banco Nacional de Desenvolvimento Econômico e Social (BNDES), Ministérios da Saúde, Ciência e Tecnologia, Educação e Economia. O que torna cada vez mais distante os esforços realizados a partir dos anos 2000 para construir capacidades locais, seja em instituições públicas, mediante transferência de ciência e tecnologia, como a Fundação Oswaldo Cruz (Fiocruz) 13 , ou instituições privadas de capital nacional.

Apesar do sucesso em capacidade produtiva e diversificação, os laboratórios públicos continuam dependendo, em grande parte, da compra de princípios ativos, particularmente da China e Índia, o que tem levado a sucessivas interrupções de fornecimentos de insumos para a produção de vacinas pelo Instituto Butantan e pela Fiocruz.

O enfrentamento da pandemia mobiliza "um sistema econômico produtivo, tecnológico e de inovação de alta complexidade, que envolve diversas indústrias e serviços e a organização dos sistemas de saúde como dimensões interdependentes" 11 (p. 27). No caso brasileiro, temos essas duas dimensões fragilizadas. Em se tratando da organização e recursos necessários ao provimento de bens e serviços para a saúde, deparamos com um SUS com agravo do subfinanciamento crônico que se materializa em um orçamento cada dia mais próximo ao piso constitucional. 


\section{Do subfinaciamento ao desfinanciamento do SUS}

Estimativas apontam que, com a Emenda Constitucional no 95/2016 7, somente entre os anos de 2018 e 2020 (excluídos os recursos extraordinários para a COVID-19), o SUS perdeu R\$22,5 bilhões de recursos federais ${ }^{14}$. Mantida a Emenda Constitucional no 95/20167, que prevê a correção do piso federal do SUS para ano subsequente apenas pela inflação, ocorrerá redução dos gastos públicos com saúde como proporção do Produto Interno Bruto (PIB) e dos gastos públicos totais, que já é um dos menores do mundo, a despeito de termos um sistema de saúde público universal 15.

Devido à natureza da crise atual, vários governos estão apostando no aumento de gastos públicos. Mesmo instituições notadamente ortodoxas, como o Banco Mundial, recomendam que os países ampliem gastos sociais e adotem medidas de apoio para os mais vulneráveis, o que reduzirá os efeitos da crise, mas não a estancará.

A despeito disso, no Brasil, as políticas de austeridade têm sido ampliadas e afetado fortemente tanto os serviços públicos de saúde como também os segmentos de pesquisa, desenvolvimento e inovação que tiveram seus orçamentos reduzidos drasticamente. O que, no âmbito da pandemia, deixou o Brasil numa situação bastante fragilizada. A compra, o desenvolvimento e a produção de vacinas é um caso emblemático da dependência tecnológica externa associada à má gestão da pandemia. Fruto do desmonte das políticas para a autonomia nacional na produção de produtos para a saúde, da desarticulação do Programa Nacional de Imunização (PNI) e do subfinanciamento da saúde e das políticas de ciência \& tecnologia e inovação (CT\&I).

A falta de planejamento do orçamento do Ministério da Saúde para o enfrentamento ao vírus SARS-CoV-2 em 2021 implicou a não previsão de recursos específicos para a pandemia em sua versão inicial enviada ao Congresso, além dos recursos não executados em 2020 para compra de vacinas no valor de R\$21,6 bilhões decorrentes de créditos extraordinários, reabertos em 2021 para esse fim. O Conselho Nacional de Saúde coletou quase 600 mil assinaturas em defesa de pelo menos R\$168,7 bilhões em 2021, excluídos os R 20 bilhões para vacinas. No entanto, o valor das despesas com ações e serviços públicos de saúde aprovado na Lei Orçamentária Anual (LOA) para 2021 foi de R\$ 131,2 bilhões 16 , enquanto o país sufoca, tendo atingido a marca de meio milhão de mortes em 19 de junho de 2021 .

\section{Considerações finais}

A articulação entre os diversos segmentos produtivos da área de saúde, redução drástica de recursos para pesquisa e desenvolvimento, educação e desfinanciamento do SUS estão entre os fatores que agravaram a pandemia da COVID-19 no país. Deixando claro que a adoção de políticas de austeridade não sustenta a construção de um CEIS que garanta um mínimo de autonomia produtiva ao país, tampouco capacidade de oferta de serviços de saúde pública à população brasileira.

O caso das vacinas evidenciou essas duas perspectivas. As parcerias do Instituto Butantan com a empresa Sinovac (China) e da Fiocruz com a Universidade de Oxford e o Laboratório AstraZeneca (Reino Unido) foram comprometidas em função dos problemas relacionados à nossa diplomacia com os países fornecedores de insumos - o que fragilizou a principal estratégia do país, focada na transferência de tecnologias via laboratórios públicos ${ }^{17}$. Isso sem considerar a negativa de compra de vacinas ofertadas por outras empresas e no âmbito da Organização Mundial da Saúde. Ao mesmo tempo, o Ministério da Saúde apresentou um orçamento para 2021 considerando a pandemia extinta e desconsiderando as demandas represadas e crescentes por serviços de saúde.

Mesmo os países que investiram no desenvolvimento e na produção de bens como vacinas não garantem equidade. Mazzucato 18 chama atenção ao fato de que "criar vacinas seguras e eficazes e criar programas de vacinação equitativos são duas coisas diferentes”. Fundamental é estabelecer parcerias público-privadas detalhadas, orientadas para a resolução de questões sociais relevantes pode garantir inovações que, além de serem eficazes, tenham propósito social. Ou seja, aproximar a lógica produtiva da lógica social requer planejamento e massivos investimentos públicos. Isso se torna impossível com as políticas de austeridade adotadas desde 2016 que, de um lado, promove o desfinanciamento do SUS, comprometendo sua sobrevivência, bem como os demais segmentos do CEIS e dos serviços 
públicos em geral. Os argumentos adotados pelos fiscalistas têm sido desconstruídos. Estudos e países mostram que há espaço para ampliar os gastos públicos, mas a opção do Brasil continua sendo a de defesa de Estado mínimo ${ }^{19}$. A tragédia que estamos vivendo mostra as consequências desta opção.

\section{Colaboradores}

E. S. Aragão contribuiu na elaboração e revisão do texto, a partir de coleta e análise de dados e documentos em colaboração com o coautor. F. R. Funcia contribuiu na coleta de dados, elaboração do texto e revisão. Ambos aprovaram a versão final para publicação.

\section{Informações adicionais}

ORCID: Erika Santos Aragão (0000-0002-49030556); Francisco Rózsa Funcia (0000-0002-54106367).

\section{Referências}

1. Gadelha CAG, Costa LS, Maldonado J. O complexo econômico-industrial da saúde e a dimensão social e econômica do desenvolvimento. Rev Saúde Pública 2012; 46 Suppl 1:21-8.

2. Gadelha CAG. O complexo industrial da saúde e a necessidade de um enfoque dinâmico na economia da saúde. Ciênc Saúde Colet 2003; 8:521-35

3. Stiglitz JE. Más instrumentos y metas más amplias para el desarrollo. Hacia el consenso post-Washington. Desarrollo Económico 1998; 38:691-722.

4. Martinez Rangel R, Reyes Garmendia ES. El consenso de Washington: la instauración de las políticas neoliberales en América Latina. Política y Cultura 2012; 37:35-64.

5. Dominguez B. Por dentro dos sistemas de saúde universais. Radis 2010; 99:11-3.

6. Tanaka OY, Oliveira VE. Reforma(s) e estruturação do Sistema de Saúde Britânico: lições para o SUS. Saúde Soc 2007; 16:7-17.

7. Brasil. Emenda Constitucional no 95, de 15 de dezembro de 2016. Altera o ato das disposições constitucionais transitórias, para instituir o Novo Regime Fiscal, e dá outras providências. Diário Oficial da União 2016; 15 dez. 
8. Brasil. Emenda Constitucional no 109, de 15 de março de 2021. Altera os arts. 29-A, 37, 49, 84, 163, 165, 167, 168 e 169 da Constituição Federal e os arts. 101 e 109 do ato das disposições constitucionais transitórias; acrescenta à Constituição Federal os arts. 164-A, 167-A, 167-B, 167-C, 167-D, 167-E, 167-F e 167-G; revoga dispositivos do Ato das Disposições Constitucionais Transitórias e institui regras transitórias sobre redução de benefícios tributários; desvincula parcialmente o superávit financeiro de fundos públicos; e suspende condicionalidades para realização de despesas com concessão de auxílio emergencial residual para enfrentar as consequências sociais e econômicas da pandemia da COVID-19. Diário Oficial da União 2021; 16 mar.

9. Brasil. Lei no 8.080, de 19 de setembro de 1990. Dispõe sobre as condições para a promoção, proteção e recuperação da saúde, a organização e o funcionamento dos serviços correspondentes e dá outras providências. Diário Oficial da União 1990; 20 set.

10. Organisation for Economic Co-operation and Development; The World Bank. Panorama de la Salud: Latinoamérica y el Caribe 2020. Paris: Organisation for Economic Co-operation and Development Publishing; 2020.

11. Gadelha CAG. O Complexo Econômico-Industrial da Saúde 4.0: por uma visão integrada do desenvolvimento econômico, social e ambiental. Cadernos do Desenvolvimento 2021; 16:25-49.

12. Dutta S, Lanvin B, Wunsch-Vincent S. The Global Innovation Index 2020: who will finance innovation? Geneva: Cornell University/ INSEAD/World Intellectual Property Organization; 2020 .
13. Homma A, Martins RM, Jessouroum E, Oliva O. Desenvolvimento tecnológico: elo deficiente na inovação tecnológica de vacinas no Brasil. Hist Ciênc Saúde-Manguinhos 2003; 10 Suppl 2: 671-96.

14. Moretti B, Ocké-Reis C, Aragão E , Funcia F, Benevides R. PEC de Bolsonaro cortará o SUS pela metade e vai afundar o Brasil ainda mais na crise econômica. Viomundo 2021; 24 fev. https://www.viomundo.com.br/blogdasaude/ economistas-advertem-austeridade-fiscal-ma ta-tirem-as-maos-do-sus.html.

15. Moretti B, Ocké C, Aragão E, Funcia F, Benevides R. Mudar a política econômica e fortalecer o SUS para evitar o caos. Abrasco: Especial Coronavírus 2020; 30 mar. https://www. abrasco.org.br/site/noticias/mudar-a-politica-economica-e-fortalecer-o-sus-para-evitar-ocaos/46220/.

16. Aragão E, Funcia F. O SUS e as políticas de austeridade: o Brasil na contramão mesmo após a crise gerada pela pandemia da COVID-19. Revista Brasileira de Planejamento e Orçamento 2021; 11:49-61.

17. Guimarães R. Vacinas anticovid: um olhar da saúde coletiva. Ciênc Saúde Colet 2020; 25:3579-85.

18. Mazzucato M. Reconstruir o estado. Project Syndicate 2021; 15 abr. https://www.projec t-syndicate.org/commentary/biden-lessonsfrom-us-moonshot-by-mariana-mazzuca to-2021-04/portuguese.

19. Dweck E, Rossi P, Matos de Oliveira AL. Economia pós-pandemia: desmontando os mitos da austeridade fiscal e construindo um novo paradigma econômico no Brasil. http://library. fes.de/pdf-files/bueros/brasilien/17101.pdf (acessado em 18/Abr/2021).
Recebido em 19/Abr/2021

Versão final reapresentada em 21/Jun/2021

Aprovado em 25/Jun/2021 